\title{
Procesos de nominación y estigmatización de los pueblos indigenas en Argentina
}

\author{
Processos de nomeação e estigmatização dos povos \\ indigenas na Argentina
}

Carina Viviana Kaplan ${ }^{1}$

Elisa Martina de los Ángeles Sulca ${ }^{2}$

\section{Resumen}

El presente artículo pretende analizar los mecanismos simbólicos subjetivos de la desigualdad social y educativa que históricamente afectan a los pueblos indígenas en Argentina negándoles derechos colectivos de inclusión para una ciudadanía democrática y para la realización personal. Nos centramos en las distintas formas de nominación y en los procesos de discriminación, inferiorización y estigmatización para dar cuenta de la matriz de sentido que, a través de sistemas de clasificación dicotómicos, establecen jerarquías y diferencias que actúan como fuente de reproducción de las desigualdades sociales y educativas. La desigualdad opera en la distribución y apropiación de los bienes culturales y en el cotidiano de las instituciones originando una estructura diferencial de oportunidades subjetivas. Los efectos subjetivos de la desigualdad atraviesan las experiencias sociales y escolares reforzando sentimientos personales y grupales de los (auto) límites simbólicos consistentes en ajustar las esperanzas y expectativas subjetivas a las probabilidades o constricciones objetivas. (KAPLAN, 2008).

\footnotetext{
1 Doctora en Educación por la UBA y Magíster en Ciencias Sociales y Educación por la FLACSO, Argentina. Posdoctorado en la Universidad Estadual de Rio de Janeiro. Profesora Titular Ordinaria de Sociología de la Educación en el Departamento de Ciencias de la Educación de la Facultad de Humanidades y Ciencias de la Educación de la Universidad Nacional de La Plata y Profesora Adjunta Regular del Departamento de Ciencias de la Educación en la FFyL de la UBA a cargo de las cátedras de Sociología de la Educación y de Teorias Sociológicas. Investigadora Independiente del CONICET. Directora del Programa de Investigación sobre Transformaciones sociales, Subjetividad y Procesos Educativos del IICE UBA. E-mail: kaplancarina@gmail.com.

${ }^{2}$ Becaria del Consejo Nacional de Investigaciones Científica y Técnica. Doctoranda en Ciencias de la Educación de la Universidad Nacional de la Plata. Facultad de Humanidades y Ciencias de la Educación. La Plata (Argentina). Profesora en Ciencias de la Educación por la Universidad Nacional de Salta (Argentina). E-mail: elysulca@gmail.com.
} 
Palabras claves: Mecanismos de Desigualdad. Procesos de nominación y estigmatización. Pueblos indigenas.

\section{Resumo}

O presente artigo pretende analisar os mecanismos simbólicos subjetivos da desigualdade social e educativa que, historicamente, afetam os povos indigenas na Argentina negando-lhes direitos coletivos de inclusão para uma cidadania democrática e para a realização pessoal. Nosso foco é nas distintas formas de nomeação e nos processos de discriminação, inferiorização e estigmatização para entender a matriz de sentido que, por meio de sistemas de classificação dicotômicos, estabelecem hierarquias e diferenças que atuam como fonte de reprodução das desigualdades sociais e educativas. A desigualdade opera na distribuição e apropriação dos bens culturais e no cotidiano das instituições, originando uma estrutura diferencial de oportunidades subjetivas. Os efeitos subjetivos da desigualdade atravessam as experiencias sociais e escolares reforçando sentimentos pessoais e coletivos dos (auto)limites simbólicos consistentes em ajustar as esperanças e expectativas subjetivas às probabilidades ou constrições objetivas (KAPLAN, 2008).

Palavras-chave: Mecanismos de Desigualdade. Processos de nomeação e estigmatização. Povos indigenas.

Abordamos la desigualdad que históricamente atraviesa a los pueblos indígenas desde una perspectiva relacional, multidimensional e histórica. Su carácter persistente se asienta en una serie de mecanismos por los cuales coexiste bajo múltiples formas.

Therborn (2015) sostiene que:

\begin{abstract}
“...la desigualdad no sea solo una cuestión de billetera: es un ordenamiento sociocultural que reduce nuestras capacidades de funcionar como seres humanos, nuestra salud, nuestro amor propio, nuestro sentido de la identidad, así como nuestros recursos para actuar y participar en este mundo". (p.9).
\end{abstract}

El autor remite a tres tipos imbricados de desigualdades: la vital, la existencial y la de recursos.

La desigualdad vital se refiere al horizonte establecido por las oportunidades de vida y acceso a la salud. La desigualdad existencial refiere 
a la asignación desigual de los atributos que constituyen a una persona, es decir, a la autonomía personal y el reconocimiento, la dignidad, los grados de libertad y el respeto. El tercer tipo de desigualdad se asocia a la desigual distribución de recursos materiales (la tierra, el dinero, las propiedades) y simbólicos (educación, relaciones sociales, oportunidades).

El fenómeno de la desigualdad genera una suerte de campos de exterminio en tanto produce fenómenos trágicos y traumáticos tales como la muerte prematura, salud deficiente, estigmatización, pobreza, impotencia, oportunidades limitadas, sentimientos de angustia, falta de amor propio, desesperanza y desconfianza del porvenir. (Therborn, 2017).

Las expresiones de la desigualdad remiten, entonces, tanto a las determinaciones objetivas como a las constricciones simbólico-subjetivas de producción de las existencias individuales y colectivas. (KAPLAN y PIOVANI, 2018).

La desigualdad que afecta a los pueblos indigenas en Argentina se enmarca en procesos de larga data que cercenan el acceso igualitario a los derechos de educación, salud, trabajo, acceso a la propiedad de la tierra, respeto a las identidades culturales y a una vida digna.

Argentina es un país profundamente heterogéneo. Según los datos del último censo poblacional (Instituto Nacional de Estadísticas y Censos, 2010) 955.032 personas se declaran indigenas o descendiente de algún pueblo indígena, esto es el 2,4 \%, sobre un total de aproximadamente 40.117.096 de habitantes.

El criterio utilizado en el censo para la identificación de las personas indígenas y su pertenencia a los distintos pueblos fue el autorreconocimiento. La encuesta censal detalló 31 pueblos indígenas: Atacama, Ava Guaraní, Aymara, Chané, Charrúa, Chorote, Chulupi, Comechingón, DiaguitaCalchaquí, Guaraní, Huarpe, Kolla, Lule, Maimará, Mapuche, Mbyá Guaraní, Mocoví, Omaguaca, Ona, Pampa, Pilagá, Quechua, Rankulche, Sanavirón, Tapiete, Tehuelche, Toba (Qom), Tonocote, Tupí Guaraní, Vilela, Wichí.

Los datos estadísticos muestran que la presencia de estos pueblos es significativa. No obstante, lejos de que la heterogeneidad fluya libremente, a 
través del tiempo se construyó un imaginario hegemónico que mediante discursos y prácticas niega, inferioriza y discrimina dichas existencias. (GRIMSON, 2017).

Las nominaciones y procesos de estigmatización e inferiorización de los pueblos indigenas están fuertemente ligadas a lo que Norbert Elias (993) ha denominado configuraciones sociales. Las configuraciones sociales conforman sistemas de interdependencia y vínculos recíprocos entre grupos sociales que a través de mutuas constricciones se mantienen a lo largo del tiempo.

Por ello, es ineludible una referencia histórica que permita comprender las relaciones sociales de subordinación y las condiciones en las que las diferencias culturales se imbrican con las desigualdades sociales en diferentes contextos sociales, económicos y políticos.

Hacia finales del siglo XIX y principio del siglo XX el Estado-naciónargentino se erigió sobre la anulación material y simbólica de los pueblos indígenas. Acompañó a las acciones de exterminio físico un discurso de alteridad, de otredad, que inscribía en el indígena expresiones de lo “peligroso”, “salvaje”, “atrasado”, “incivilizado” (ÁLVAREZ LEGUIZAMÓN, 2017). Los pueblos indígenas constituían un obstáculo para el desarrollo y el progreso de la nación que se inspiró en un modelo hegemónico europeo.

Oszlak (1982) señala que la instauración de un modelo hegemónico en Argentina se realizó a través cuatro modalidades: represiva (mediante el uso de la fuerza militar para prevenir y sofocar rebeliones en todo el ámbito nacional) cooptativa (para establecer alianzas entre los grupos dominantes locales y gobiernos provinciales tendientes a preservar y consolidar el sistema de dominación impuesto en el orden nacional) material (localización de obras, servicios y regulaciones indispensables para el progreso económico del país) e ideológica (a través de la educación para difundir valores hegemónicos, con el objetivo de crear conciencia e identidad nacional y castellanizar la lengua).

Sobre estos pueblos se ha operado mediante la violencia física $y$ simbólica, el aniquilamiento físico, el despojo continuo de sus tierras, religiones, lenguas, culturas, el desplazamiento forzado de sus lugares de residencia. Todo ello implicó la progresiva anulación de las culturas indígenas 
y diversas formas de integración subalternizada a la nueva organización social y politica del país.

Los procesos de exterminio y negación de los pueblos indígenas convergieron en la creación de una "nación imaginariamente blanca descendiente de europeos y sin indios". (NOVARO y HETCH, 2017, p.59).

A principio del siglo XXI ha comenzado a emerger la conciencia de un país habitado por la diversidad cultural. En este marco, el Estado argentino reconoció la existencia de los diferentes pueblos indígenas y el acceso a derechos fundamentales a través de marcos legales tales como Reforma Constitucional (1994), el Convenio 169 de la Organización Internacional del Trabajo (OIT) (2000), la Ley de Educación Nacional N²6.206 (2006) y la ley $\mathrm{N}^{\circ} 26.160$ de emergencia en materia de posesión y propiedad de las tierras que ocupan los pueblos indígenas del país (2007). Estas normativas apelan, entre otras cuestiones, a la garantía de los derechos (lenguas, educación, identidad, sistema de valores, reconocimiento, acceso a la tierra) y al respeto a las culturas indígenas.

Sin embargo, el avance en el plano jurídico no implicó necesariamente transformación de los imaginarios y las barreras emocionales de la sociedad Argentina, pues estos pueblos son objeto de discriminación, sometimiento e inferiorización que se expresan en el orden de lo simbólico, tales como las nominaciones peyorativas, los caracteres negativizados sobre el color de la piel, las prácticas culturales.

De alli que los logros en relación al reconocimiento de la diversidad deben ser matizados, ya que:

\footnotetext{
"algunas diferencias continúan invisibilizadas, otras sometidas a fuertes proceso de discriminación, otras son celebradas de modo superficial, es decir, en argentina se asume la existencia de una vasta heterogeneidad sociocultural que está, al mismo tiempo, escasamente visibilizada o fuertemente invisibilizada". (GRIMSON, 2017, p.24).
}

En base a estas consideraciones ponemos el foco en la matriz oculta que a lo largo de la historia argentina generó las condiciones para la producción y reproducción de la trama de las desigualdades. 
La diferenciación entre un "nosotros" y "ellos" permitió desplegar una serie de estrategias de regulación y de control de esa alteridad construida de los pueblos indígenas. La imagen de un "nosotros" superior se expresó en formas de nombrar, en prácticas, gustos, que pretendian ser reflejo de una cultura hegemónica occidental, frente a un "otro" inculto, incivilizado" que habia que asistir mediante prácticas tipificadas como civilizatorias. (ÁLVAREZ LEGUIZAMÓN, 2017).

Desde un enfoque superador para interpretar las relaciones de dominación, Elias sostiene que someter al otro al ostracismo es un paso preliminar para establecer distancia y desapego entre grupos. En un marco de interacciones el grupo de mayor poder estigmatiza al grupo de menor poder para conservar su identidad, reafirmar su superioridad y mantener a los otros en su sitio. "Un grupo puede estigmatizar efectivamente a otro en la medida que se encuentre bien instalado en posiciones de poder a las que el otro grupo ve negado el acceso". (2003, p.224).

Las diferencias establecidas entre formas de vida "moderna" y "atrasada", lengua "oficial” y lenguas "no oficiales", civilizados y bárbaros constituyeron un régimen de clasificación para el ordenamiento concreto de un escalafón social. En base a estas valoraciones negativas se construyó una relación jerárquica legitimadora de la desigualdad con los pueblos indígenas.

Estos pares categoriales hoy se expresan de maneras eufemizadas, pero con la misma fuerza discriminatoria y estigmatizante que en sus inicios. Los procesos de inclusión/exclusión de los pueblos coexisten en un marco de tensiones permanentes.

Therborn identifica cuatro mecanismos por los cuales se reproduce la desigualdad: distanciamiento, exclusión, jerarquización y explotación.

El distanciamiento es un proceso sistémico que se desarrolla en sistemas preparados para forjar ganadores y perdedores, exitosos y fracasados, así como una distancia de recompensas y ventajas entre ellos. La exclusión impide avanzar o acceder a ciertas personas o grupos. Therborn explica este mecanismo como un conjunto de obstáculos que se coloca delante de una persona o grupo e impide, pone techos, crea "muros simbólicos" 
(KAPLAN, 2016), genera discriminaciones de diverso tipo. El mecanismo de la jerarquización es una expresión del racismo dado que ubica a algunos sectores sociales arriba y otros abajo en una escala de supraordenación y subordinación. La explotación entraña una división asumida como esencial entre personas superiores y personas inferiores, en cuyo marco, las primeras de manera unilateral y asimétrica extraen valores de las segundas.

Los cuatro mecanismos ocultos operan de manera interrelacionada generando ciertos resultados distributivos. Actúan tanto a nivel marco (en regiones de economía mundial) como a nivel micro (en las instituciones escolares).

La discriminación e inferiorización estructural hacia integrantes de pueblos indígenas por el color de piel, las pautas culturales, las creencias, lengua, marcó profundamente las subjetividades.

La inferiorización persiste a través de discursos coloquiales, estereotipos, nominaciones que se enmarcan en aspectos cotidianos e institucionales dando lugar a su reproducción. "El leguaje, sea verbal o corporal, opera en el territorio de lo simbólico y de sus luchas”. (KAPLAN, 2016, p. 211).

La estigmatización incluye actos de violencia en la medida en que socava la autoimagen de un grupo con menor poder, "la debilita, la desarma" (ELIAS, 2003, p.225). De allí que sobre el reconocimiento de la diversidad cultural pueden desplegarse sentimientos de vergüenza de la identidad o el ocultamiento de la pertenencia indigena por temor a la discriminación y relegación en las instituciones sociales. (GRIMSON, 2017).

La estigmatización paraliza, causa daños en quienes la padecen. Este efecto paralizante puede incluso contribuir a perpetuar durante cierto tiempo la superioridad de un grupo sobre otro. Elias señala que mientras el diferencial de poder sea grande y la sumisión inevitable, los grupos de menor poder experimentan emocionalmente su inferioridad de poder como un signo de inferioridad humana.

En el marco de estas relaciones diferenciales de poder, los dominados contribuyen, sin saberlo, a su propia dominación al aceptar las concepciones 
dominantes sobre su calidad humana, sus posibilidades, potencialidades, limitaciones. La inferioridad suele expresarse en la forma de emociones corporales y sentimientos: miedo, vergüenza, humillación, culpabilidad. (Kaplan, 2008).

Bourdieu manifiesta que la vivencia de inferioridad puede expresarse en la postura corporal o en el sentimiento de vergüenza en virtud de su calidad humana.

El sentimiento de vergüenza es una señal del "dolor social” en un doble sentido: es inflingido socialmente por la gente que "avergüenza" (como castigo) y demostrado socialmente por otra persona que es avergonzada (como expiación). "La persona que se avergüenza siente que ha dañado su propia posición y está en peligro de humillación y expulsión, y permite saber a los demás que lo reconoce" (GOUDSBLOM, 2008, p.23).

El control de los comportamientos, en un marco de relaciones, permite mantener un orden social legitimado. En este aspecto, el estigma funciona como una coacción externa que expone al individuo a un sentimiento de vergüenza con el propósito de regular su conducta impulsiva y afectiva.

Therborn considera que "la estigmatización es un indicador de la desigualdad que abre heridas incurables en los que se quedan afuera". (2015, p. 63). Sentimientos de inferioridad, vergüenza, dolor, miedo, desconfianza, pocas o nulas expectativas, son algunos efectos de la estigmatización.

Para Goffman (2008) el estigma es un atributo diferenciador que marca a quién o a quienes lo portan y está dado en función de un prototipo construido socialmente. Los procesos de estigmatización se insertan en el corazón de las relaciones de poder y cada proceso de desacreditación y discriminación social está estrechamente vinculado con la clase, género, raza, edad, u orientación sexual.

Respecto a las formas de nominar a los pueblos indigenas éstas han variado en función de los contextos sociohistóricos. Actualmente existen diferentes categorias para referir a los pueblos: autóctonos, aborígenes, nativos. Con la misma intención se emplean referencias tales como: minorías, etnias, comunidades, poblaciones. 
Tales nominaciones refieren a los indígenas como actores monolíticos o grupos homogéneos en tanto eliminan la heterogeneidad de los distintos pueblos, sus formas de organización, de participación política, de los procesos de identificación.

Las implicancias sociales y subjetivas que acarrea las nominaciones son traducidos en etiquetamientos y categorias que justifican discursos y prácticas de exclusión y discriminación social.

Las nominaciones sociales se fabrican con la eficacia de las palabras que se muestran como neutrales, sin embargo, poseen efectos en la esfera de la dominación simbólica. Todo acto descriptivo es, a la vez, una anticipación prescriptiva. Según Bourdieu:

\footnotetext{
"Las palabras ejercen un poder típicamente mágico: hacen ver, hacen creer, hacen actuar. Pero como en el caso de la magia, es necesario preguntarse dónde reside el principio de esa acción o, con mayor exactitud, cuales son las condiciones sociales que hacen posible la eficacia mágica de las palabras. El poder de las palabras no se ejerce sino sobre quienes han estado dispuestos a oírlas y escucharlas, en resumen, a creerlas. (2015, p. 196)
}

A través del lenguaje se construye realidad. Las palabras y los nombres tienen un poder estructurador, que, bajo la apariencia de describir, prescriben, así como también la de denunciar bajo la apariencia de enunciar. Lo cierto es que los nombres operan como categorias sociopoliticas. Los ritos de nominación sucesivos a través de los cuales se elabora una identidad social, efectuados bajo el control y con la garantía del Estado, desarrollan una descripción oficial de esta especie de esencia social que el orden social instituye a través del nombre propio. (KAPLAN, 2008).

En la construcción de imaginarios hegemónicos no se dejó de lado las corporalidades (GRIMSON, 2017), que al jerarquizarlas legitimaron un color de piel y ciertos rasgos físicos. Una piel blanca, de linaje europeo, por sobre otra piel morena, oscura, negra, de linaje no europeo. En las corporalidades no hegemónicas se encuentran, entre otros, los indígenas en quienes se inscribieron rasgos fenotípicos que aparecen como esencias, "ocultando la biologización y esencialización de los social. El color de piel se jerarquiza. Una 
piel se presenta como superior mientras que la otra es inferior. No todos los colores ni las tonalidades comparten idéntica valoración en las jerarquías sociales". (KAPLAN, 2016, p.213).

La apelación al aspecto físico, o a los rasgos corporales, comprenden un elemento central del racismo. La identificación de marcas ancladas en la corporalidad como el rostro, la piel, el cuerpo facilitan la identificación del otro, establecen una línea diferenciadora entre un nosotros y ellos. Esta apelación a lo biológico facilita la identificación del otro y esencializa la marca de su inferioridad humana y social (GOFFMAN, 2006).

La piel oscura, el cabello negro, ciertas relaciones con la cultura parecen ser atributos de lo indigena (ÁLVAREZ LEGUIZAMÓN, 2017, p14) que al naturalizarlas reifican las relaciones de poder a partir de mecanismos que parecen racionales y que, en realidad son del orden de los sentimientos, de las creencias que se construyen a partir de esas desigualdades jerarquizadas.

El rostro y el color de la piel hablan de nosotros y por nosotros, delimitando las relaciones entre nosotros y ellos, ya que "no todos los colores ni las tonalidades comparten idénticas valoraciones en las jerarquías sociales. La piel, en muchas ocasiones, se utiliza como eufemismo de origen de clase: a tales pieles, tales destinos" (KAPLAN, 2016, p, 212).

El cuerpo, y más particularmente el rostro, al estar tratados socialmente a través de sus marcas, más o menos visibles, más o menos invisibles, producen subjetividad, por lo que la mirada de los otros, en determinadas instancias, dan valor o lo quitan (KAPLAN, 2016). "La mirada tiene una fuerza simbólica cuya intensidad es difícil de suprimir. Los ojos del otro están dotados de privilegio, de otorgar o quitar significados esenciales". (LE BRETON, 2010, p.134).

Asimismo, la idea de "progreso", de "desarrollo nacional" y de "modernización del país" se imbrican fuertemente con el proceso de inferiorización de las culturas indigenas consideradas "atrasadas", "estancadas". Estos discursos se traducen en la expropiación de la tierra y de los recursos de supervivencia de los pueblos. Bajo el amparo de estos discursos en la Argentina se desmontaron 118.000 hectáreas entre 1998 y 
2002 para la producción de soja en Chaco, 160.000 en Salta y 223.000 en Santiago del Estero, este proyecto conlleva, además, una cadena de eventos que destruyen los hábitats naturales de grandes áreas y de la deforestación causada por la expansión de terrenos para el cultivo de soja. (ÁLVAREZ LEGUIZAMÓN, 2017).

La expropiación de la tierra no implica solamente la desposesión en términos materiales, ya que para los pueblos indigenas la noción de tierra excede a la superficie que constituye, es la flora, fauna, ríos, lagos, montañas, cultura, incluye una pluralidad de significados materiales y simbólicos. La tierra constituye una de las dimensiones identitarias más importantes de lo indigena.

Las consecuencias de la expansión del cultivo de la soja ha sido la expulsión violenta de los territorios, migración forzosa a las ciudades, empobrecimiento en los asentamientos de las periferias urbanas con la ocupación de indigenas expulsados de sus territorios, entre otros. (ÁLVAREZ LEGUIZAMÓN, 2017).

Estamos en presencia de lo que algunos autores (ÁLVAREZ LEGUIZAMÓN, 2017, GRIMSON, 2017) han denominado "racismo indio", que, ante caracteres como el color de la piel oscura vinculado a antepasados nativos, ciertas relaciones con la cultura y el aspecto, conforman imaginarios que actúan como fuente de reproducción de las desigualdades sociales.

Manrique (2003) asevera que el racismo cumple una función decisiva en la legitimación de las exclusiones, pues naturaliza las desigualdades sociales. En la dinámica social, el racismo es, ante todo, una ideología y como tal, sirve para consagrar un status quo determinado, de manera que va cambiando de acuerdo a como cambian las relaciones socioeconómicas y las correlaciones de poder establecidas.

Las lógicas del racismo están tensionadas por principios de inferiorización y diferenciación que pretende marginar, excluir o incluso destruir a un determinado grupo.

Wieviorka señala que: 


\begin{abstract}
"No se puede pensar y analizar el racismo sin observar sus manifestaciones concretas y el contexto en el que se expresan, El racismo debe ser considerado como el fruto de situaciones y de cambios en los que acompaña y funda vínculos sociales. (...) El racismo no sólo es un fenómeno meramente ideológico, político o doctrinario, es decir, un conjunto de modos de pensamiento que remitiria a la historia de las ideas y de la filosofia política, sino que debe ser comprendido como un componente de conductas entre grupos humanos que toman la forma de prejuicio, de la discriminación y de la segregación (..) pero también de la violencia. (2009, p.51, citado en KAPLAN, 2016).
\end{abstract}

Bourdieu (1948) sostiene que "las expresiones del racismo se han censurado, por lo cual la pulsión racista sólo puede expresarse en formas muy eufemizadas y con la máscara de la denegación" (p.201).

Álvarez Leguizamón (2017) manifiesta que "el racismo en los pueblos indigenas se activa por procesos concadenados que van desde las renovadas formas de nominación a las múltiples formas de expropiación de los medios de subsistencia”. (p,311).

El corolario de estos mecanismos simbólicos es la extracción de los recursos, la limitación de posibilidades, la expulsión de espacios sociales. Se trata de una desigualdad existencial, en tanto se asigna una distribución desigual de la autonomía, la libertad, la dignidad, el respeto, las posibilidades de desarrollo de una persona o grupo social. "Se explota en el amor, el respeto, la admiración de otra persona: se usa para ventaja propia dando poco o nada a cambio" (THERBORN, 2015, p.62)

Estos mecanismos pueden ser analizados dentro de la escuela, pues en ella y a través de ella se reproducen desigualdades sociales, a su vez esta institución produce sus propias marcas exclusoras.

Las jerarquías que se establecen al interior de la escuela entre "exitosos" y "fracasados", "buenos" y "malos" alumnos se inscriben en desigualdades sociales e históricas. Tales desigualdades inciden en la apropiación diferencial del conocimiento, en las trayectorias escolares, en las constituciones subjetivas de quienes transitan el sistema educativo.

Bourdieu (1999) en su interpretación de las diferencias en los resultados escolares que presentan niños y niñas de diferentes clases sociales respecto 
del "éxito escolar", manifiesta que las trayectorias escolares están condicionadas por el capital cultural acumulado por la familia.

Este capital puede existir bajo tres formas: en estado incorporado (se encuentra ligado al cuerpo y supone la incorporación, es un capital "personal"), en estado objetivado (se define en relación al estado incorporado y es transmisible en su materialidad) y en estado institucionalizado (capital cultural bajo la forma de títulos).

En efecto, el capital cultural acumulado por la familia implica un tiempo de inversión que antecede a los hijos, no depende de ellos, pero condiciona sus trayectorias escolares que tienden a reproducirse a lo largo de generaciones. (KAPLAN, 2017).

Vale destacar que la educación para los niñas, niñas y jóvenes indígenas no ha sido un derecho garantizado por el Estado. Aun con el establecimiento de la educación intercultural bilingüe ${ }^{3}$ los indices de escolarización de los indigenas son bajos.

"Los datos del Relevamiento Anual (2007) de la Dirección Nacional de Información y Evaluación de la Calidad Educativa (Diniece) del Ministerio de Educación, muestra que, a nivel nacional, en las escuelas primarias de EIB, la tasa promedio de promoción de los alumnos es del $81 \%$, mientras que en las escuelas de educación común es de $93 \%$. Esta diferencia, según se explica, se debe a las altas tasas de reprobación (15\%), abandono (4\%) y sobreedad (55\%), valores que superan ampliamente a los de las escuelas de educación común (6, 2 y $22 \%$ respectivamente). (NOVARO y HECHT, 2017, p. 63)

La relación entre el capital cultural familiar de los y las estudiantes indigenas y el capital cultural escolar se enmarca en diferencias profundas y hasta contradictorias en tanto la escuela imparte un capital cultural de la ideología dominante que se expresa desde el lenguaje, los comportamientos hasta las formas de ver la realidad. El patrón cultural que imparte la escuela no coincide con las prácticas culturales, las lenguas, las formas de comunicación, las culturas de los y las estudiantes indigenas.

\footnotetext{
${ }^{3}$ Educación Intercultural Bilingüe es una modalidad del sistema educativo argentino que garantiza el derecho de los pueblos indígenas "a recibir una educación que contribuya a preservar y fortalecer sus pautas culturales, su lengua, su cosmovisión e identidad étnica; a desempeñarse activamente en un mundo multicultural y a mejorar su calidad de vida" (Ley de Educación Nacional N²6.206, capítulo XI, artículo 52)
} 
De alli que los exitosos serán los tienen los mismos códigos que maneja la escuela ya que no habrá distancia alguna entre el capital cultural escolar y el capital cultural familiar. La distribución desigual del capital cultural incide en las expectativas subjetivas.

\footnotetext{
"En cuanto a sus expectativas y aspiraciones, también se hallan muy desigualmente repartidas (...), en virtud de la ley que establece que, por mediación de las disposiciones del habitus (a su vez ajustadas, las más de las veces, a las posiciones), las esperanzas tienden universalmente a acomodarse a las posibilidades objetivas". (BOURDIEU, 1999, p.287)
}

Lo cierto es que la condición de pobreza caracteriza a los pueblos indigenas y constituye una doble desventaja para permanecer en la escuela.

Las trayectorias estudiantiles se ven marcadas por procesos de exclusión de diversos tipos a partir de las cuales tienden a percibirse a sí mismos como causa última de su propio fracaso; se desacreditan como producto del descrédito del que han sido objeto. (KAPLAN, 2008).

En este marco las trayectorias, experiencias y resultados escolares diferenciales de los sujetos indígenas se inscriben en disposiciones simbólicas para el "éxito" o el "fracaso" escolar. La ideología de los talentos naturales es el dispositivo principal para explicar el éxito o el fracaso social y educativo (KAPLAN, 2008), escindido de las condiciones socioeconómicas y de las responsabilidades politicas.

Las creencias acerca de los "dones" y los "talentos" operan como predicciones o anticipaciones, es decir como construcciones simbólicas que estructuran los límites y las expectativas respecto de los estudiantes de sectores sociales desfavorecidos. (KAPLAN, 2008).

\footnotetext{
"Estos tipos de discursos concuerdan con las lógicas meritocráticas biologicistas deterministas que ponen énfasis en las características intrínsecas de los individuos y grupos para el logro del éxito y fracaso social, sea para la movilidad social o para la concreción de los estudios". (KAPLAN, 2008, p. 155).
} 
Es decir, las diferencias sociales se transmutan en diferencias de orden natural constit.

Entonces, es importante dar cuenta de cómo el sistema escolar contribuye a la reproducción del orden social sobre la base de creencias que adquieren consecuencias prácticas. Esto es, las apreciaciones que tienen los docentes acerca de sus estudiantes operan como predicciones y anticipaciones que estructuran los limites y expectativas.

La exclusión por parte del sistema educativo se lleva adelante a través de "formas negadas de eliminación" (BOURDIEU, 1998), es decir, mediante mecanismos implícitos y paulatinos como la repitencia, el abandono escolar, entre otras.

Bourdieu plantea que para que la escuela pueda asegurar la reproducción social debe dotarse de un sistema de representaciones fundamentadas sobre una ideología o una creencia, de manera que las prácticas nieguen el proceso de dominación simbólica.

A lo largo de la historia, las argumentaciones reduccionistas biologicistas, centradas en las características genéricas de los individuos, se correlacionan con episodios de retroceso político, en especial con las campañas para reducir el gasto del Estado en los programas sociales, o a veces por el temor de las clases dominantes, cuando los grupos desfavorecidos siembran cierta intranquilidad social o incluso amenazan con usurpar el poder. (KAPLAN, 2008)

No obstante, "en las sociedades complejas siempre hay un margen de espacio para que algunos individuos "gambeteen el sistema", pero los casos ocasionales de distanciamiento individual con respecto a la multitud no anulan per se el patrón general de la desigualdad". (THERBORN, 2017, p.61).

En el marco de estas consideraciones, se denomina "logro" al éxito alcanzado por el "esfuerzo" de quienes no están en igualdad de condiciones respecto a la uyendo uno de los mecanismos más potentes de exclusión social disposición del capital cultural. Este mecanismo oculta la producción de la desigualdad al asignar recompensas legítimas" (THERBORN, 2017, p.60). 
Novaro y Hecht (2017) manifiestan que la nueva retórica de reconocimiento de la diversidad cultural en la escuela trae consigo renovados mecanismos que reproducen la desigualdad en su interior.

El dualismo se renueva con la frontera de lo "indigena" y lo "no indígena", lo "tradicional" y lo "moderno", que lleva a desvalorizar y deslegitimar las manifestaciones indigenas contemporáneas en tanto existen esencialismos y estereotipos respecto a la cultura, lengua, visión, religiones, formas de vestir, de vivir de estos pueblos. Las autoras sostienen que:

\footnotetext{
"En la escuela, a pesar de la difusión de posiciones indigenistas en muchos docentes, a estas caracteristicas de la propuesta oficial se agregan las estrategias de simplificación y comparación que muchas veces estereotipan los términos, desconectan los rasgos y refuerzan la naturalización". (NOVARO, 2003, p.214).
}

El reconocimiento de la diversidad cultural en el ámbito de la escuela, en muchos casos se transforman en políticas de marcación y fijación de la diferencia étnica. Es decir, la cultura indigena en la escuela se presenta de forma esencializada, fija, estancada, de modo que se quita su agencia histórica.

Estas concepciones propician procesos de exclusión de los pueblos indígenas de los diferentes ámbitos: de la educación, el esparcimiento, de la seguridad, de la justicia, del respeto, la valoración de las culturas, de las oportunidades laborales, de las posibilidades de desarrollo.

La desigualdad que atraviesa a los pueblos indígenas es existencial, en tanto existe una violación de la dignidad humana de estos grupos porque se les niega la posibilidad de que desarrollen sus capacidades, su potencial humano, participen de las decisiones politicas, es decir, se les niega el derecho a vivir dignamente.

No obstante, la desigualdad y la exclusión se fundan en un espacio social que no se ejercen sin prácticas de resistencia, contestación y sumisión, en tanto "forman una red de interdependencias mutuas que se tocan, conviven, ya la vez se resisten y excluyen unos a otros". (KAPLAN, 2016, p. 110). 
La desigualdad de los pueblos indigenas ha sido persistente. Si bien, en los últimos años se evidencia un avance en la ampliación de derechos de estos grupos, los muros simbólicos que se fueron conformando en las relaciones sociales marcan una distancia afectiva por parte de la sociedad en general.

Elias señala que, tal vez por encima de cualquier otra variable la barrera emocional explica, a menudo, la extrema rigidez de la actitud por parte de los grupos con mayor poder frente a los grupos con menor poder. Esta relación de poder puede estar presente durante generaciones, y ello, aunque su superioridad, es decir su excedente de poder, se encuentre en disminución. La inflexibilidad emocional se asienta en sentimientos de virtud humana superior.

Siguiendo lo planteado por Elias, las relaciones de poder entre grupos divergentes no son estáticas ni esencialistas. Por el contrario, revisten de carácter dinámico, a lo que Elias denomina "sociodinámica de la estigmatización". Añade también que la capacidad de estigmatizar está en función del poder que presenta un grupo en un momento histórico o coyuntura dada, y que el equilibrio de poder entre ese grupo y el que es estigmatizado puede alterarse e ir modificándose.

"El poder de estigmatizar disminuye cuando un grupo ya no es capaz de preservar su monopolio de los principales recursos de poder disponibles en una sociedad y de excluir a otros grupos interdependientes de la participación en dichos recursos. Tan pronto como las disparidades de poder o, dicho de otra forma, la desigualdad en el equilibrio de poder disminuye, entonces los grupos anteriormente foráneos tienden a desquitarse. Recurren a la contraestigmatización." (ELIAS, 2003, p.225).

Identificamos el autorreconocimiento y la autopercepción como indígena una forma de resistencia y de contra estigmatización, en tanto existe una valoración de la propia cultura que antes fue negada e inferiorizada. Esta valoración de la cultura y la identidad indígena se convierte en un estandarte de lucha.

Respecto a la dinámica de la estigmatización Goffman sostiene que el grupo estigmatizado puede resignificar el atributo negativo otorgado por el 
grupo dominante y construir su autoidentificación en términos positivos y utilizarlo como estandarte de lucha por los derechos negados.

Goffman (2008), aporta a la comprensión acerca de cómo los estigmatizados, en este caso los pueblos indígenas, elaboran una determinada salida de su situación y la convierten en bandera de lucha por sus derechos. El autor sostiene que:

\begin{abstract}
"cuando el objetivo político último es suprimir la diferencia provocada por el estigma, el individuo puede descubrir que esos mismos esfuerzos son capaces de politizar su propia vida, volviéndola aún más diferente que la vida normal que se le negó inicialmente, aun cuando las generaciones posteriores de compañeros saquen buen provecho de esos esfuerzos al obtener una mayor aceptación. Además, al llamar la atención sobre la situación de su propia clase, consolida en ciertos aspectos una imagen pública de su diferencia como algo real y de sus compañeros de infortunio como grupo real." (2008: 145).
\end{abstract}

El tránsito que implicó el paso de una invisibilidad histórica a una visibilidad persistente de los pueblos indígenas tuvo lugar en un marco de acciones concretas, por ejemplo, las organizaciones y manifestaciones de los distintos pueblos indígenas, que con fuerza creciente reclaman el derecho a la tierra, educación intercultural, participación politica, respeto a la identidad, entre otras.

\title{
Consideraciones finales
}

La desigualdad es un fenómeno multidimensional que no se circunscribe exclusivamente a la distribución de los recursos económicos, sino que también compromete la dignidad humana en la medida en que concierne a la distribución diferencial de oportunidades y capacidades de funcionamiento entre los individuos y grupos sociales.

El fenómeno de la desigualdad que atraviesa a los pueblos indígenas persiste pese a la vigencia de marcos legales que reconocen su existencia. La desigualdad social de estos pueblos se reproduce a través de discursos y prácticas, que muchas veces provienen del orden del sentido común que reactualizan las fronteras de exclusión/inclusión, produciendo marcas 
subjetivas que se expresan en la negación de la identidad, el sentimiento de vergüenza, hasta la autoexclusión.

Novaro y Hecht muestran a través de sus investigaciones sobre educación, diversidad y desigualdad de indígenas y migrantes en Argentina, que la escuela se movió en las tensiones dadas por el reconocimiento y la negación de pueblos indígenas, supuestamente abierta a la inclusión, pero sin lograr que sean parte. Los imaginarios sociales construidos en torno a estos grupos han penetrado de modo subordinado en la escuela, "mediante el silenciamiento, a partir de su asociación con "lo tradicional", término que parece condensar las ambigüedades de la valorización y la desvalorización de lo considerado como distinto y lejano a los supuestos parámetros de normalidad escolar". (2017, p.74).

Es necesario poner de relieve el valor insoslayable que posee la escuela para los niños, niñas y jóvenes indigenas atravesados por condiciones subjetivas y materiales de pobreza y discriminación, en tanto, las prácticas que en ella tengan lugar pueden atenuar las marcas de la desigualdad durante el proceso de escolarización.

Como se puede visualizar a través del desarrollo de este artículo, la desigualdad, la estigmatización, la exclusión, el racismo operan como una matriz oculta, que de formas diferentes reproduce un orden social que deja en desventaja siempre a los pueblos indígenas. El "muro simbólico" que separa entre un "nosotros" y "ellos" en términos de inferioridad, de carencia, de valor humano se hace visible en los discursos y las prácticas.

\section{Referencias bibliográficas}

ÁLVAREZ LEGUIZAMÓN, S. Formas de racismo indio en Argentina y configuraciones sociales de poder. Rosario, Argentina: Prohistoria Ediciones. 2017.

BOURDIEU, P. Meditaciones pascalianas. Barcelona: Anagrama. 1999.

BOURDIEU, P. y SAINT MARTÍN, M. Las categorías del juicio profesoral. En Actes de la Recherche en Sciences Sociales. París, Francia, p. 4-18. 1998. 
ELIAS, N. Civilización y violencia. Revista Española de Investigaciones Sociológicas, 65, 141-152. 1994.

ELIAS, N. El proceso de la civilización. Investigaciones sociogenéticas y psicogenéticas. México: Fondo de Cultura Económica. 1987.

ELIAS, N. Ensayo acerca de las relaciones entre establecidos y forasteros. Revista $N^{\circ} 104$, p. 219-225. 2003.

ELIAS, N. La civilización de los padres y otros ensayos. Santafé de Bogotá, Barcelona: Grupo Editorial Norma. 1998.

GOFFMAN, E. Estigma. La identidad deteriorada. Buenos Aires, Argentina: Amorrortu Editores. 2008.

GOUDSBLOM, J.La vergüenza como dolor social. C. V. KAPLAN, La civilización en cuestión. Escritos inspirados en la obra de Norbert Elias (pp. 13-28) Buenos Aires, Argentina: Miño y Dávila. 2008.

GRIMSON, A Y KARASIK, G. Introducción a la heterogeneidad sociocultural. A, Grimson, y G.Karasik,Estudios sobre diversidad sociocultural en la Argentina contemporánea (pp.15-24) Buenos Aires, Argentina: Consejo Latinoamericano de Ciencias Sociales. 2017.

KAPLAN, C. V. Comportamiento individual y estructura social: cambios y relaciones. Una lectura desde Norbert Elias. C. V. KAPLAN, La civilización en cuestión. Escritos inspirados en la obra de Norbert Elias (pp.1515-168) Buenos Aires, Argentina: Miño y Dávila. 2008.

KAPLAN, C. V. El lenguaje es una piel. Género, violencia y procesos civilizatorios. C. V. KAPLAN, Género es más que una palabra. Educar sin etiquetas (pp.211-223) Buenos Aires, Argentina: Miño y Dávila. 2016.

KAPLAN, C. V. El racismo de la violencia. Aportes de la sociología figuracional. C. V. KAPLAN y M. SARAT, Educación y procesos de civilización. Miradas desde la obra de Norbert Elias (pp.99-118) Buenos Aires, Argentina: Colección saberes. 2016. 
KAPLAN, C. V. y PIOVANI, I. Trayectorias y capitales socioeducativos.I. PIOVANIy A. SALVIA, La argentina en el siglo XXI: cómo somos, vivimos y convivimos en una sociedad desigual. Encuesta nacional sobre la estructura social (pp.221-263) Buenos Aires, Argentina: Siglo XXI. 2018.

KAPLAN, C.V. Talentos, dones e inteligencias. El fracaso escolar no es un destino. Buenos Aires, Argentina: Ediciones Colihue. 2008.

LE BRETON, D. Rostros. Ensayo de antropología. Buenos Aires, Argentina: Letra Viva. 2010.

MARGULIS, M. "La racialización de las relaciones de clase”. M. MARGULIS; M. URRESTI y otros (Edit.) La segregación negada. Cultura y discriminación social (37-62) Buenos Aires, Argentina: Biblos. 1998.

NOVARO, G y HECHT, C. Educación, diversidad y desigualdad en Argentina. Experiencias escolares de poblaciones indigenas y migrantes. Revista Argumentos. Estudios criticos de la sociedad, 30, (84),57-76. 2018.

NOVARO, G. "indios”, “aborígenes" y "pueblos originarios" sobre el cambio de conceptos y la continuidad de las concepciones escolares. Educación, lenguaje y sociedad, I (1), 199-219. 2003.

OSZLAK, O. La conquista del orden político y la formación histórica del estado nacional. Buenos Aires, Argentina: Editorial CEDES. 1982.

THERBORN, G. Los campos de exterminio de la desigualdad. Buenos Aires, Argentina: Fondo de Cultura Económica de Argentina. 2015. 